\title{
Nódulos presentes en leguminosas asociadas a pasturas de Brachiaria sp en la Amazonia Colombiana
}

\author{
Blanco, J.C.,; Páramo, A.Y.'; Montilla, M.A. ${ }^{3}$ \\ Grupo de investigación GIPSA ${ }^{1,2}$, Semillero de Investigación SIEPSA, Universidad \\ de la Amazonia, Florencia (Caquetá, Colombia) ${ }^{3}$. E-mail: ju.blanco@udla.edu.co
}

\begin{abstract}
Resumen
Blanco, J.C.; Páramo, A.Y.; Montilla, M.A.: Nódulos presentes en leguminosas asociadas a pasturas de Brachiaria sp en la Amazonia Colombiana. Rev. Vet. 32: 1, 89-94, 2021. Se estudiaron 23 pasturas de Brachiaria sp dedicadas a la producción bovina doble propósito, para identificar especies de leguminosas presentes y obtener muestras de raíces para extracción y recuento de nódulos. Toda el área correspondió a un total de 149,14 ha, donde solo 84,26 ha contaban con la presencia de leguminosas Desmodium sp, Pueraria phaseoloides, Galactia striata, Arachis pintoi, Stylosanthes sp, Mimosa púdica y Centrosema sp, cuya cobertura fue del $2,89 \%$ de dicha área. La especie con mayor porcentaje de cobertura promedio fue A.pintoi con 5,36\% seguida de Stylosanthes $s p$ con $5 \%$, G. striata con $3,89 \%$ y P.phaseoloides con $2,62 \%$. Las restantes se encontraron en un rango inferior a $2 \%$ del área de pastura. Se halló en el estudio un mínimo de 7 nódulos en raíces de Centrosema sp y G.striata, así como un número máximo de 194 nódulos en Desmodium sp. Las cantidades superiores a 100 nódulos por planta solo correspondieron a Desmodium sp, el cual reveló una inoculación satisfactoria que se asoció con su potencial de fijación de nitrógeno mediada por simbiosis. La especie con menor número de nódulos fue $M$. púdica, hallada en el 4,3\% de las pasturas evaluadas, siendo la única de las leguminosas muestreadas que no es consumida directamente por los bovinos y se desarrolla como especie no deseada, indicadora de estados de degradación de pasturas.
\end{abstract}

Palabras clave: leguminosas, nodulación, pasturas, Brachiaria sp.

\begin{abstract}
Blanco, J.C.; Páramo, A.Y.; Montilla, M.A.: Nodules present in leguminous associated to pastures of Brachiaria sp in the Colombian Amazonia. Rev. Vet. 32: 1, 89-94, 2021. Twenty-three Brachiaria sp. pastures were studied, dedicated to dual purpose bovine production to identify species of legumes present and obtain root samples for extraction and nodule counting. The entire area corresponded to a total of 149.14 ha, where only 84.26 ha had the presence of the legumes Desmodium sp. Pueraria phaseoloides, Galactia striata, Arachis pintoi, Estilosantes sp, Mimosa púdica and Centrosema $s p$, whose coverage was $2.89 \%$ of that area. The species with the highest percentage of average coverage was A.pintoi with 5.36\% followed by Stylosanthes $s p$ with 5\%, G.striata with 3.89\% and P.phaseoloides with $2.62 \%$. The rest were found in a range of less than $2 \%$ of the pasture area. A minimum of 7 nodules were found in the roots of Centrosema sp. and G.striata and a maximum number of 194 nodules in Desmodium sp. The amounts greater than 100 nodules per plant only corresponded to Desmodium $s p$, which reveals a satisfactory inoculation that is associated with its potential for nitrogen fixation mediated by symbiosis. The species with the lowest number of nodules was M.pudica found in $4.3 \%$ of the pastures evaluated, being the only one of the legumes sampled that is not consumed directly by bovines and develops as an unwanted species, indicating degradation levels of pastures.
\end{abstract}

Key words: legumes, nodulation, pastures, Brachiaria sp.

\section{INTRODUCCIÓN}

La fijación del nitrógeno funciona en bacterias adaptadas a ambientes ecológicos y estilos de vida muy diversos. Sin embargo, todas poseen el sistema enzimá- tico responsable de la reducción del nitrógeno, para lo cual requieren un nicho específico dentro de las células de órganos llamados nódulos ${ }^{28}$.

Dichos nódulos son formados por las raíces de las leguminosas, como resultado de la penetración de rizobacterias donde se lleva a cabo la fijación de nitrógeno ${ }^{17}$, sin descartar que existen otros lugares como el 
tallo de las plantas ${ }^{28}$ donde este proceso se puede llevar a cabo.

Para la formación de nódulos es necesaria la síntesis y liberación de moléculas pequeñas por parte de las bacterias, las cuales son detectadas por la planta, provocándose la nodulación ${ }^{13}$. Estas moléculas son denominadas factores $\mathrm{Nod}$, que al ser detectados por las leguminosas inducen grandes cambios en el desarrollo de la planta, necesarios para la entrada de los rizobios en el hospedero ${ }^{5}$.

Aproximadamente el $90 \%$ de las especies de plantas leguminosas pueden llegar a formar nódulos, aunque existe una especificidad marcada entre las especies de leguminosas y las cepas de Rhizobium ${ }^{17}$. Cada cepa de estas bacterias puede, por lo general, infectar a ciertas especies de leguminosas y no a otras.

Se denomina inoculación cruzada a todo el grupo de cepas de Rhizobium que pueden infectar a un grupo de especies próximas de leguminosas. Igualmente, las cepas efectivas forman nódulos mayores, rojizos y fijadores de nitrógeno que contienen un pigmento denominado "hemoglobina de los nódulos" la cual interviene en la fijación de nitrógeno ${ }^{25}$

La excreción de factores de crecimiento por parte de las raíces de las leguminosas permite el crecimiento de los nódulos ${ }^{10}$, de tal manera que las bacterias invaden los pelos radicales que presentan ruptura hasta llegar a la endodermis y al periciclo, a partir de lo cual se producen divisiones celulares y el nódulo crece rápidamente, aumentando el volumen en dirección a la superficie de la raíz.

Cuando las bacterias colonizan la superficie de la raíz, inducen a la formación de una curvatura de la raíz en las vellosidades de las puntas o rizado. Las bacterias quedan atrapadas dentro de la bolsa del rizo en donde la pared celular vegetal se degrada localmente, la membrana celular se invagina y el nuevo material depositado es una mezcla de planta y bacterias ${ }^{13}$.

Además, en la superficie de la raíz se degradan las paredes celulares de la planta, permitiendo que los rizobios atrapados en los pelos de la misma, se desarrollen como una infección que crece dentro de las vellosidades de la raíz ${ }^{1}$.

Las células corticales de la raíz son inducidas a un proceso de diferenciación que se observa por la ampliación de las células y en el sitio de infección o hilo, los rizobios se multiplican, pero permanecen confinados por la pared celular vegetal ${ }^{12}$, lo cual se observa como un nuevo nódulo.

El número de nódulos en las leguminosas depende de varios factores, como la temperatura, la exposición a la luz, la presencia de nitrógeno y los niveles de $\mathrm{CO}_{2}$, determinando el almacenamiento de carbohidratos en la planta, favoreciendo la producción de nódulos ${ }^{2}$.

La planta es la que controla principalmente el número de nódulos, mediante un mecanismo de autorregulación, el cual también es controlado por factores externos como la presencia de nitratos en el suelo.
Igualmente, la cantidad de nódulos depende de la fertilidad del suelo, es decir, de los nutrimentos minerales $(\mathrm{P}, \mathrm{K}, \mathrm{Mg}, \mathrm{Ca})$ presentes en él, todo ello relacionado con la eficiencia de la fijación de nitrógeno.

Por otra parte, diversos factores afectan la simbiosis, frenando la aparición de nódulos. Por ello, el número de nódulos depende de la familia o cepa de Rizobios y de las características genéticas de la planta. Sin embargo, cuando hay una necrosis en los tejitos de la planta, se reduce el proceso de nodulación y la efectividad de los microorganismos en la fijación de nitrógeno, reduciéndose el número de nódulos.

Por lo anterior, el objetivo del presente artículo es reconocer el potencial de nodulación de diferentes especies de leguminosas asociadas a pasturas de $\mathrm{Bra}$ chiaria sp en el Centro de Investigaciones Macagual de la Universidad de la Amazonia (Colombia), que puede verse reflejado en el número de nódulos producidos por especie, para generar información que permita una selección adecuada de especies para la alimentación de bovinos en pastoreo, las cuales dinamizan el ciclo del nitrógeno y contribuyen al aumento en los niveles de producción animal.

\section{MATERIAL Y MÉTODOS}

Debido a que el número de nódulos se relaciona con la inoculación de Rhizobium en las especies de leguminosas, se llevaron a cabo diferentes actividades que permitieron reconocer aspectos inherentes a la presencia de leguminosas en diferentes áreas de pastura, reconociendo su potencial de nodulación dados sus efectos sobre el crecimiento de la planta y la producción animal.

\section{Identificación de especies de leguminosas presentes en pasturas}

El estudio se realizó en el Centro de Investigaciones Macagual de la Universidad de la Amazonia, donde se llevó a cabo un muestreo de la cobertura de forma sistemática en 23 lugares; realizando lanzamientos en zig zag de un marco de $1 \mathrm{~m}^{2}$ el cual permite cubrir tanto especies estoloníferas o rastreras y erectas ${ }^{11}$, debido a que las pasturas en el departamento de Caquetá presentan alta heterogeneidad a causa de la interacción con fragmentos de bosque, por lo cual este tamaño es necesario ya que se recomienda para pasturas no homogéneas y en áreas que presentan suelo descubierto ${ }^{18}$.

En cada una de las 22 pasturas se llevaron a cabo 50 lanzamientos del marco ${ }^{19} \mathrm{en}$ forma de zigzag sistematicamente ${ }^{9}$, a fin de cubrir la mayor cantidad de area debido a la misma heterogeneidad de la pastura con el fin de poder ubicar los sitios donde se encontraban las leguminosas dispersas en cada uno de los potreros ${ }^{26} \mathrm{y}$ lograr una estimación acertada del porcentaje de cobertura de las especies, lo cual puede estar relacionado con la cantidad de nitrógeno en el suelo ${ }^{29}$. 
tallo de las plantas ${ }^{28}$ donde este proceso se puede llevar a cabo.

Para la formación de nódulos es necesaria la síntesis y liberación de moléculas pequeñas por parte de las bacterias, las cuales son detectadas por la planta, provocándose la nodulación ${ }^{13}$. Estas moléculas son denominadas factores $\mathrm{Nod}$, que al ser detectados por las leguminosas inducen grandes cambios en el desarrollo de la planta, necesarios para la entrada de los rizobios en el hospedero ${ }^{5}$.

Aproximadamente el $90 \%$ de las especies de plantas leguminosas pueden llegar a formar nódulos, aunque existe una especificidad marcada entre las especies de leguminosas y las cepas de Rhizobium ${ }^{17}$. Cada cepa de estas bacterias puede, por lo general, infectar a ciertas especies de leguminosas y no a otras.

Se denomina inoculación cruzada a todo el grupo de cepas de Rhizobium que pueden infectar a un grupo de especies próximas de leguminosas. Igualmente, las cepas efectivas forman nódulos mayores, rojizos y fijadores de nitrógeno que contienen un pigmento denominado "hemoglobina de los nódulos" la cual interviene en la fijación de nitrógeno ${ }^{25}$

La excreción de factores de crecimiento por parte de las raíces de las leguminosas permite el crecimiento de los nódulos ${ }^{10}$, de tal manera que las bacterias invaden los pelos radicales que presentan ruptura hasta llegar a la endodermis y al periciclo, a partir de lo cual se producen divisiones celulares y el nódulo crece rápidamente, aumentando el volumen en dirección a la superficie de la raíz.

Cuando las bacterias colonizan la superficie de la raíz, inducen a la formación de una curvatura de la raíz en las vellosidades de las puntas o rizado. Las bacterias quedan atrapadas dentro de la bolsa del rizo en donde la pared celular vegetal se degrada localmente, la membrana celular se invagina y el nuevo material depositado es una mezcla de planta y bacterias ${ }^{13}$.

Además, en la superficie de la raíz se degradan las paredes celulares de la planta, permitiendo que los rizobios atrapados en los pelos de la misma, se desarrollen como una infección que crece dentro de las vellosidades de la raíz ${ }^{1}$.

Las células corticales de la raíz son inducidas a un proceso de diferenciación que se observa por la ampliación de las células y en el sitio de infección o hilo, los rizobios se multiplican, pero permanecen confinados por la pared celular vegetal ${ }^{12}$, lo cual se observa como un nuevo nódulo.

El número de nódulos en las leguminosas depende de varios factores, como la temperatura, la exposición a la luz, la presencia de nitrógeno y los niveles de $\mathrm{CO}_{2}$, determinando el almacenamiento de carbohidratos en la planta, favoreciendo la producción de nódulos ${ }^{2}$.

La planta es la que controla principalmente el número de nódulos, mediante un mecanismo de autorregulación, el cual también es controlado por factores externos como la presencia de nitratos en el suelo.
Igualmente, la cantidad de nódulos depende de la fertilidad del suelo, es decir, de los nutrimentos minerales $(\mathrm{P}, \mathrm{K}, \mathrm{Mg}, \mathrm{Ca})$ presentes en él, todo ello relacionado con la eficiencia de la fijación de nitrógeno.

Por otra parte, diversos factores afectan la simbiosis, frenando la aparición de nódulos. Por ello, el número de nódulos depende de la familia o cepa de Rizobios y de las características genéticas de la planta. Sin embargo, cuando hay una necrosis en los tejitos de la planta, se reduce el proceso de nodulación y la efectividad de los microorganismos en la fijación de nitrógeno, reduciéndose el número de nódulos.

Por lo anterior, el objetivo del presente artículo es reconocer el potencial de nodulación de diferentes especies de leguminosas asociadas a pasturas de $\mathrm{Bra}$ chiaria sp en el Centro de Investigaciones Macagual de la Universidad de la Amazonia (Colombia), que puede verse reflejado en el número de nódulos producidos por especie, para generar información que permita una selección adecuada de especies para la alimentación de bovinos en pastoreo, las cuales dinamizan el ciclo del nitrógeno y contribuyen al aumento en los niveles de producción animal.

\section{MATERIAL Y MÉTODOS}

Debido a que el número de nódulos se relaciona con la inoculación de Rhizobium en las especies de leguminosas, se llevaron a cabo diferentes actividades que permitieron reconocer aspectos inherentes a la presencia de leguminosas en diferentes áreas de pastura, reconociendo su potencial de nodulación dados sus efectos sobre el crecimiento de la planta y la producción animal.

\section{Identificación de especies de leguminosas presentes en pasturas}

El estudio se realizó en el Centro de Investigaciones Macagual de la Universidad de la Amazonia, donde se llevó a cabo un muestreo de la cobertura de forma sistemática en 23 lugares; realizando lanzamientos en zig zag de un marco de $1 \mathrm{~m}^{2}$ el cual permite cubrir tanto especies estoloníferas o rastreras y erectas ${ }^{11}$, debido a que las pasturas en el departamento de Caquetá presentan alta heterogeneidad a causa de la interacción con fragmentos de bosque, por lo cual este tamaño es necesario ya que se recomienda para pasturas no homogéneas y en áreas que presentan suelo descubierto ${ }^{18}$.

En cada una de las 22 pasturas se llevaron a cabo 50 lanzamientos del marco ${ }^{19} \mathrm{en}$ forma de zigzag sistematicamente ${ }^{9}$, a fin de cubrir la mayor cantidad de area debido a la misma heterogeneidad de la pastura con el fin de poder ubicar los sitios donde se encontraban las leguminosas dispersas en cada uno de los potreros ${ }^{26} \mathrm{y}$ lograr una estimación acertada del porcentaje de cobertura de las especies, lo cual puede estar relacionado con la cantidad de nitrógeno en el suelo ${ }^{29}$. 


\section{Muestreo de raices}

En cada uno de los sitios donde se halló el marco de $1 \mathrm{~m}^{2}$ se evaluó la densidad de especies de leguminosas al interior del perímetro (Universidad Nacional de Córdoba, 2015). Posteriormente se llevó a cabo la metodología de recuperación de nódulos en campo planteada por otros investigadores ${ }^{6}$, a través de la cual se separan las especies de leguminosas marcando un radio de aproximadamente $15 \mathrm{~cm}$ alrededor de la planta con una pala y cortando esta sección a una profundidad aproximada de $20 \mathrm{~cm}$.

Siguiendo el método propuesto por otros investigadores ${ }^{24}$, se usó una pala para levantar lentamente el conjunto de raíces de la planta, retirando cuidadosamente el material de la raíz con las manos, teniendo la precaución de no separar raíces secundarias de la planta, ya que se pueden encontrar nódulos en ellas que pueden ser aislados en el laboratorio tal y como lo mencionan otros investigadores ${ }^{15}$.

Las raíces fueron introducidas en bolsas de cierre hermético ${ }^{4}$, debidamente rotuladas e identificadas, para ser almacenadas en un termo de poliestireno, con el fin de mantener sus condiciones físicas ${ }^{22}$ para el trabajo de laboratorio.

\section{Extracción y recuento de nódulos}

Para obtener la mayor cantidad de nódulos procedentes de las raíces de leguminosas muestreadas en el campo, se utilizó la metodología planteada por Prévost $\&$ Antoun ${ }^{21}$, a través de la cual se utiliza una malla que se coloca debajo de cada muestra de raíz para atrapar los nódulos que puedan desprenderse de la raíz, se lavan cuidadosamente las raíces con un chorro suave de agua de grifo y posteriormente se separan para el secado sobre papel de filtro.

Posteriormente, se llevó a cabo un recuento de nódulos procedentes de cada una de las raíces de las plantas obtenidas en campo, a fin de obtener el número por especie y por pastura.

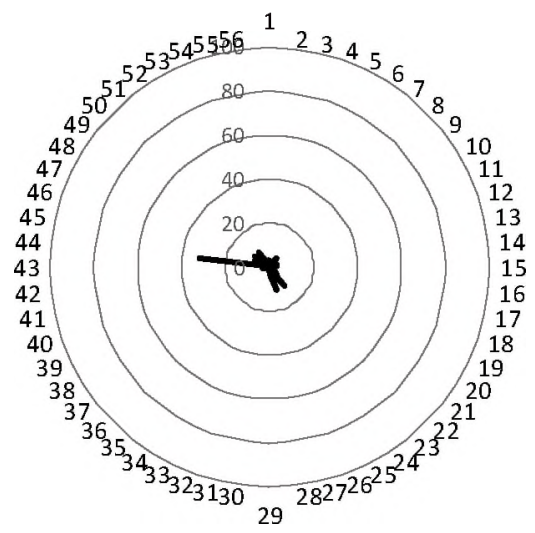

\section{RESULTADOS Y DISCUSIÓN}

\section{Especies de leguminosas asociadas a pasturas de Brachiaria}

De las 23 pasturas muestreadas cuya área total correspondió a 149,14 ha, se encontró que solo el 56,5\% de ellas contaban con presencia de leguminosas, correspondiente a las especies Desmodium sp, Pueraria phaseoloides, Galactia striata, Arachis pintoi, Estilosantes sp., Mimosa púdica y Centrosema sp. Las demás pasturas evaluadas no se incluyeron en el análisis ya que no presentaron leguminosas como ya se mencionó.

Tal y como se evidencia en la gráfica anterior, la distribución de las leguminosas sobre el total de la cobertura vegetal presente en las 13 pasturas donde fueron halladas $(84,62 \mathrm{ha})$ es incipiente, ya que en ningún caso superó el $10 \%$ del área de cada pastura, obteniéndose un promedio general de cobertura de leguminosas de $2,89 \%$ lo cual es bajo, frente al total de las áreas de pastura (2,44 ha ocupadas por leguminosas).

Sin embargo, estas especies generan efectos positivos en los sistemas donde interactúan mejorando los niveles de nitrógeno en el suelo, con tendencia hacia el aumento de carbono en el suelo y la PPN (productividad primaria neta) como respuesta a la mejoría en la fertilidad del suelo ${ }^{32} \mathrm{y}$ al incremento en la capacidad fotosintética de las plantas por aumentos en los niveles de nitrógeno en su biomasa ${ }^{31}$, previniendo el proceso de degradación de las pasturas.

La especie con mayor porcentaje de cobertura promedio fue Arachis pintoi con 5,36\% seguida de Stylosanthes $s p$. con $5 \%$, Galactia striata con 3,89\% y Pueraria phaseoloides con 2,62\%. El resto se encontraron en un rango que no superó el $2 \%$ del área de la pastura.

Lo anterior, se relaciona con un bajo porte observado en las pasturas evaluadas, principalmente en aquellas con ausencia de leguminosas, ya que el crecimiento de la biomasa se estimula a través de la fijación de nitrógeno atmosférico ejercido por las leguminosas ${ }^{25}$.

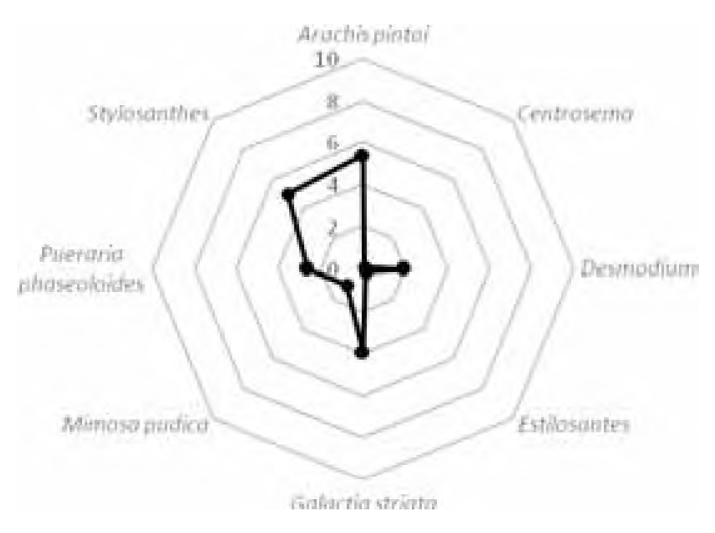

Figura 1. Porcentaje de cobertura de leguminosas identificadas en pasturas de Brachiaria sp. Izquierda: distribución de cobertura de las leguminosas identificadas sobre el 100\% de las pasturas evaluadas. Derecha: cobertura de leguminosas identificadas superpuestas en el 10\% del área de pasturas. 


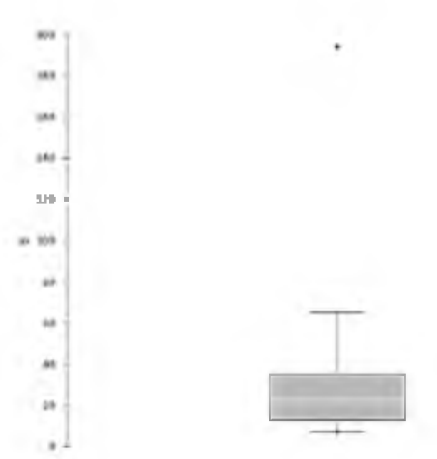

Figura 2. Distribución de la cantidad de nódulos presentes en las especies de leguminosas identificadas en las diferentes pasturas.

Tal y como sucede en la mayoría de pasturas tropicales, en la zona evaluada no se aplican abonos industriales debido a los altos costos que requiere la fertilización de grandes extensiones destinadas a pastoreo y por el rechazo que genera actualmente este tipo de productos frente a la relación estrecha que posee con las emisiones de $\mathrm{GEI}^{8} \mathrm{y} \mathrm{NH}_{3}{ }^{30}$

\section{Número de nódulos encontrados en las especies de leguminosas}

Como resultado del conteo de nódulos de todas las especies leguminosas muestreadas, se encontró una cantidad mínima de 7 nódulos en raíces de un individuo de Centrosema sp. y en dos de Galactia striata ubicadas en diferentes áreas de pastura y un número máximo de 194 nódulos encontrados en raíces de plantas de un solo individuo de Desmodium $s p$ como datos atípicos.

En la Figura 2 se puede observar que el número de nódulos en las diferentes especies de leguminosa presentó una media de 33 y una mediana de 22. Algunos indican que independientemente de la especie de leguminosa, un número aproximado de 15 nódulos en sus raíces ${ }^{20}$ refleja una función apropiada de las bacterias fijadoras de nitrógeno, con ajustes en la fisiología y el metabolismo de las plantas, en respuesta a una progre- sión simbiótica ${ }^{13}$ evidenciada en la presencia de nódulos. Esto indica que la actividad fijadora de nitrógeno es mayor en las pasturas donde se encuentran leguminosas con alto número de nódulos.

Los casos con cantidad superior a 100 nódulos/ planta se encontraron en la especie Desmodium $s p$ en dos individuos que presentaron 179 y 174 nódulos/ planta, ubicados en dos pasturas diferentes, valores que reflejan una inoculación satisfactoria y una condición de simbiosis eficiente; sin embargo es necesaria una mayor investigación para afirmar si esta situación representa equivalencia con una alta tasa de fijación de nitrógeno ${ }^{20}$.

Según la Tabla 1, Desmodium $s p$ fue la leguminosa que presentó mayor cantidad promedio de nódulos en sus raíces, lo cual coincide con previas investigaciones ${ }^{7}$ halladas en el $39,1 \%$ de las pasturas evaluadas, seguida por Stylosanthes $s p$ cuya frecuencia fue menor, encontrándose en el $8,6 \%$ de las pasturas.

Este resultado es superior al obtenido por otros investigadores ${ }^{23}$ que reportan un promedio de 8 nóludos por individuo en condiciones de sabana tropical brasileña, pero es inferior a los hallados por otros, quienes encontraron aproximadamente 54 nódulos por cada planta ${ }^{14}$. Sin embargo, a diferencia de estos dos estudios, el ejercicio llevado a cabo en las pasturas del Centro de Investigaciones Macagual no fueron estimuladas con productos químicos ni biológicos; es decir, que la nodulación ocurrió de forma natural en la pastura.

Cabe resaltar que pese a la baja frecuencia ya mencionada dentro del estudio, esta especie presentó una alta abundancia en las pasturas donde se encontró.

Por otra parte, los individuos de Galactia striata ostentaron la mayor frecuencia en las pasturas evaluadas, pero la cantidad promedio de nódulos no presentó la misma característica; aun así, al igual que en los resultados obtenidos con Stylosanthes sp el número de nódulos refleja una adecuada fijación de nutrientes si se compara con otros casos donde se aplicaron soluciones nutritivas ${ }^{16} \mathrm{y}$ ha sido indudable una cantidad de nódulos superior.

Tabla 1. Promedio de nódulos presentes en las especies de leguminosas halladas en cada una de las pasturas evaluadas.

\begin{tabular}{|c|c|c|c|c|c|c|c|}
\hline pastura & $\begin{array}{c}\text { Desmodium } \\
\text { sp. }\end{array}$ & $\begin{array}{c}\text { Pueraria } \\
\text { phaseoloides }\end{array}$ & $\begin{array}{c}\text { Galactia } \\
\text { striata }\end{array}$ & $\begin{array}{c}\text { Arachis } \\
\text { pintoi }\end{array}$ & $\begin{array}{c}\text { Stylosanthes } \\
\text { sp. }\end{array}$ & $\begin{array}{c}\text { Mimosa } \\
\text { pudica }\end{array}$ & $\begin{array}{c}\text { Centrosema } \\
\text { sp }\end{array}$ \\
\hline 1 & 11 & 44 & 24 & 25 & - & - & - \\
\hline 2 & - & 15 & 16 & 20 & 45 & - & - \\
\hline 3 & 94 & - & 32 & 30 & - & - & - \\
\hline 4 & - & 11 & 13 & 25 & - & - & 7 \\
\hline 5 & - & - & & - & - & 16 & - \\
\hline 6 & - & - & 35 & - & - & - & - \\
\hline 11 & 28 & - & 10 & - & - & - & 35 \\
\hline 12 & 16 & - & & 15 & - & - & 50 \\
\hline 13 & 11 & - & 7 & - & - & - & - \\
\hline 18 & 7 & - & 26 & - & - & - & 24 \\
\hline 19 & 22 & 10 & 23 & - & - & - & 12 \\
\hline 20 & 64 & - & 19 & - & 34 & - & 15 \\
\hline 23 & 77 & - & 20 & 12 & - & - & - \\
\hline
\end{tabular}


Finalmente, la especie con menor cantidad de nódulos correspondió a Mimosa puidica, hallada solamente en el $4,3 \%$ de las pasturas evaluadas en la investigación, contrariamente a lo reportado por quien obtuvo una mayor cantidad de los mismos en sus raíces ${ }^{27}$. Al igual que en casos anteriores, los valores superiores a la cantidad de nódulos encontrados en la investigación desarrollada corresponden al uso de estimulantes químicos o microbiológicos, aspecto que permite indicar que estos individuos introducidos en las pasturas presentan una relación directa entre el número de nódulos y su potencial de fijación de nitrógeno.

Cabe reiterar, tal y como se evidencia en la Tabla 1, que solo 13 de las 23 pasturas muestreadas presentaron leguminosas en su cobertura. Esta situación, a razón de que no todas presentan la asociación gramínea-leguminosa, considera que en la Amazonia colombiana se ha efectuado la conversión de bosque primario en pastizales para pastoreo, creados a partir de procesos de deforestación bajo la premisa de monocultivos de gramíneas, definidos como no apropiados, no viables e insostenibles ${ }^{3}$.

Sin embargo, en los últimos años, algunos productores optaron por la asociación de gramíneas y leguminosas a fin de mejorar sus indicadores productivos y mitigar el proceso de degradación, razón por la cual pueden hallarse pasturas con características similares a las identificadas durante el muestreo.

Agradecimientos. Los autores agradecen a la Universidad de la Amazonia por la aprobación del presente proyecto, al Vicerrector por facilitar los trabajos y a los estudiantes que apoyaron las labores de campo.

\section{REFERENCIAS}

1. Acosta C. 2005. Los árboles fijadores de nitrógeno y sus mecanismos biológicos, p. 9: 23-27.

2. Alexander M. 1994. Introducción a la microbiología del suelo, 2da. ed., E.García Libros y Editoriales S.A., Mexico, D.F.

3. Arcila N. et al. 2000. Construcción de un territorio amazónico en el siglo XX. Edit. Tercer Mundo, Bogotá, D.C.

4. Avella DJ. 2007.Caracterización molecular de cepas nativas colombianas de Azotobacter sp mediante el análisis de restricción del DNA ribosomal 16s. Pontificia Universidad Javeriana.

5. B.Guasch V. 2011. Selección y caracterización de mutantes de Rhizobium tropici CIAT899 afectados en la producción de factores nod en condiciones de estrés salino. Universidad de Sevilla.

6. Bécquer CJ, Prévost, D. 2014. Revista Cubana de Ciencia Agricola, 480 p, 301-307.

7. Bosman H et al. 1990. Composición botánica y nodulación de leguminosas en las pasturas nativas de la planicie costera del Golfo de México. Pasturas Tropicales 12: 1, p 2-8.

8. Carvalho LR et al. 2019. Nodulation and biological nitrogen fixation (BNF) in forage peanut (Arachis pintoi) $\mathrm{cv}$.
Belmonte, subjected to grazing regimes. Agriculture, Ecosystems \& Environment, Elsevier, p. 96-106.

9. Castrillo RF. 2005. El muestreo de suelos, Edit. Ministerio de Agricultura y Ganadería, Costa Rica, Imprenta Nacional.

10. Farías RR, Sánchez MJ. 2005. Inoculación de leguminosas con Rhizobium. Edit. Mexico.

11. Franco LH, Calero QD, Durán CV. 2006. Manejo y utilización de forrajes tropicales multipropósito, 1ra. Ed., Centro Internacional de Agricultura Tropical, CIAT Edit. Univ. Nac.de Colombia, doi: 10.5216/ree.v16i1.20132.

12. Galindo MA. 2000.Sintesis de glutatión y homoglutatión en nódulos de leguminosas. Estación Experim.Aula Dei, Consejo Superior de Investigaciones Científicas.

13. Garg N, Renseigné N. 2009. Symbiotic nitrogen fixation in legume nodules: process and signaling: A review. Sustainable Agriculture, p. 519-531.

14. Gates CT. 1974. Nodule and plant development in Stylosanthes humilis HBK: symbiotic response to phosphorus and sulphur, Australian Journal of Botany, 22: 45-55.

15. Hernández JL, Cubillos JG, Milian PE. 2012. Aislamiento de cepas de Rhizobium sp asociados a dos leguminosas forrajeras en el Centro Biotecnológico del Caribe, Rev Colomb de Microbiol Trop 2: 2, 1-13.

16. Lopes ES et al. 1974. Seleção de estirpes de Rhizobium sp para amendoim (Arachis hypogaea L.) e galáxia (Galactia striata). Bragantia, 33: 104-110.

17. Madigan M, Martinko J, Parker J. 2003. Brock Biologia de los Microorganismos, $10^{\circ}$ Ed., Edit. P. Educacion, USA.

18. McMeniman N. 1997. Methods of estimating intake of grazing animals. Juiz de Fora, 34.

19. Mendoza R, Espinoza A. 2017. Guía técnica para muestreo de suelos, Nicaragua.

20. Pommeresche R, Hansen S. 2017. Examining root nodule activity on legumes, Fertil Crop Technical Note. Available at: http://orgprints.org/31344/1/tn-wp5.pdf.

21. Prévost D, Antoun H. 2008. Root nodule bacteria and symbiotic nitrogen fixation (Chapter 31). In: Carter MR (ed.): Muestreo de suelo y métodos de análisis, $2 \mathrm{da}$ edición, Canadian Society of Soil Science, pp. 379.397.

22. Recinos CD, García GF. 2007.Aislamiento, evaluación y selección de cepas simbioticas nativas de Rhizobium sp en Phaseolus vulgaris de suelos agricolas de El Salvador. Tesis, Universidad de El Salvador.

23. Silva $\mathbf{K}$ et al. 2017.Isolamento e diversidades de bactérias fixadoras de nitrógeno obtidas de diferentes espécies de estilosantes no cerrado de roraima. Documentos Boa Vista: 62 .

24. Somasegaran P, Hoben HJ. 1985. Handbook for Rhizobia, Springer, New York, doi: 10.1007/978-1-4613-8375-8.

25. Thomas RJ. 1992. The role of the legume in the nitrogen cycle of productive and sustainable pastures. Grass \& Forage Science 47: 2, 133-142.

26. Universidad Nacional de Córdoba. 2015. Guía de actividades prácticas de micro- biología agrícola, Facultad de Ciencias Agropecuarias, Córdoba, Colombia 
27. Vergueiro DC. 2009. Nodulação de Mimosa pudica 1 por beta-rizóbio isolados de diferentes ecossistemas no Brasil. Universidade Federal Rural, Rio de Janeiro.

28. Wang S. et al. 2018. Nitrogen fixation reaction derived from nanostructured catalytic materials, advanced functional materials. Wiley-VCH Verlag 28: 50, p.1-26.

29. Wei X, Reich PB, Hobbie SE. 2019. Legumes regulate grassland soil $\mathrm{N}$ cycling and its response to variation in species diversity and $\mathrm{N}$ supply but not $\mathrm{CO}^{2}$ '. Global Change Biology, Blackwell Publishing Ltd, doi: 10.1111/ gcb. 14636 .
30. Xu R et al. 2019. Global ammonia emissions from synthetic nitrogen fertilizer applications in agricultural systems: Empirical and process-based estimates and uncertainty, Global Change Biology 25: 1, 314-326.

31. Xu Z, Zhou GS. 2006. Nitrogen metabolism and photosynthesis in Leymus chinensis in response to long-term soil drought. Journal Plant Growth Regul 25: 252-266.

32. Zhao J. et al. 2014. Legume-soil interactions: legume addition enhances the complexity of the soil food web. Plant Soil 385: 273-286.

\section{SClmago Journal \& Country Rank}

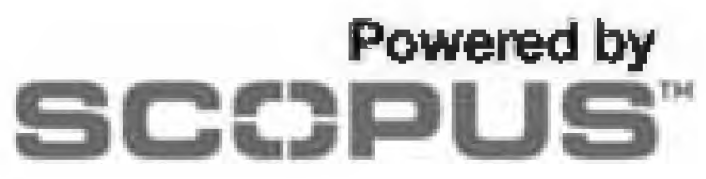

\section{Revista Veterinaria mantiene su índice de impacto}

Noticias de Scimago Research Group (Scimago Journals \& Country Ranks, Scopus-Elsevier) comunican que la publicación de nuestra casa, Revista Veterinaria, aumentó su índice de impacto. El índice SJR mide la influencia científica (impacto) del artículo de una revista, expresando cuán importante es el "artículo promedio" de la publicación en la discusión científica global (sistema Thomson Reuters).

Para nuestra revista, tal indicador había sido de 0,03 entre 2008 y 2011, aumentando a 0,05 en 2012, a 0,11 en 2013, a 0,108 en 2015, a 0,100 en 2017 y a 0,114 (Research Gate) en 2018, último período evaluado. Asimismo, surge para nuestra publicación un sostenido descenso del indicador que relaciona "citas versus autocitas", demostrando que los autores de los artículos están abandonando la práctica de citar sus propias publicaciones anteriores.

Por último, se advierte que según este portal, nuestra "Revista Veterinaria" continúa siendo la única publicación de esta rama de la ciencia que posee índice de impacto en Argentina. Para el resto del cono sur tal distinción recae en Brasil, Chile, Colombia y Venezuela. En revistas de veterinaria, a nivel mundial el mayor índice de impacto (2,911 puntos) recae en Annual Review of Animal Biosciences (Estados Unidos). 